\title{
EPIDEMIOLOGY OF PNEUMOCYSTIS PNEUMONIA IN PATIENS WITHOUT HIV INFECTION IN SPAIN (2008-12)
}

Pereira-Díaz E., López Alfaro R., Moreno-Verdejo F., Giménez-Miranda L., Martínez- Risquez M., Varela J.M., Calderón E., Medrano F.J.

Internal Medicine. Virgen del Rocio University Hospital, San Juan de Dios del Aljarafe Hospital and Institute of Biomedicine of Seville, CIBERESP, Spain

\section{INTRODUCTION AND PURPOSE}

$>$ In developed countries a substantial decline in the incidence of Pneumocystis pneumonia (PcP) has been observed in HIV-patients after the widespread use of anti-Pneumocystis chemoprophylaxis and with the introduction of highly active antiretroviral therapy during the 1990s. However, the incidence of this infection seem to be growing among nonHIV patients, whose risk features are worse defined and where there is few available information in our country.

> THE AIM of this study was to evaluate the incidence, risk factors and epidemiological features of PcP in non-HIV patients during the 2008-2012 period in Spain.
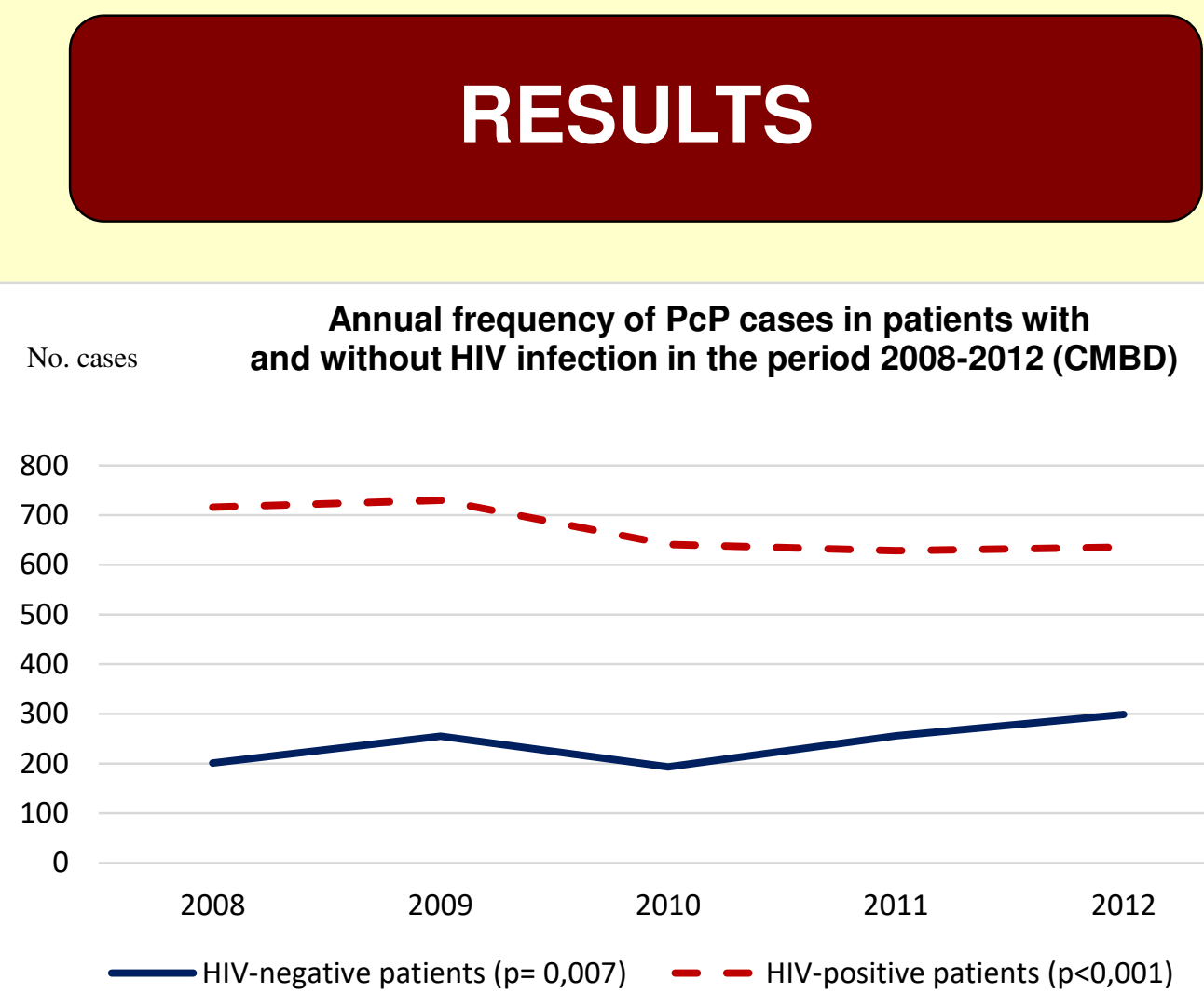

CMBD, Basic Minimun Set of Data

\section{Seasonal distribution}

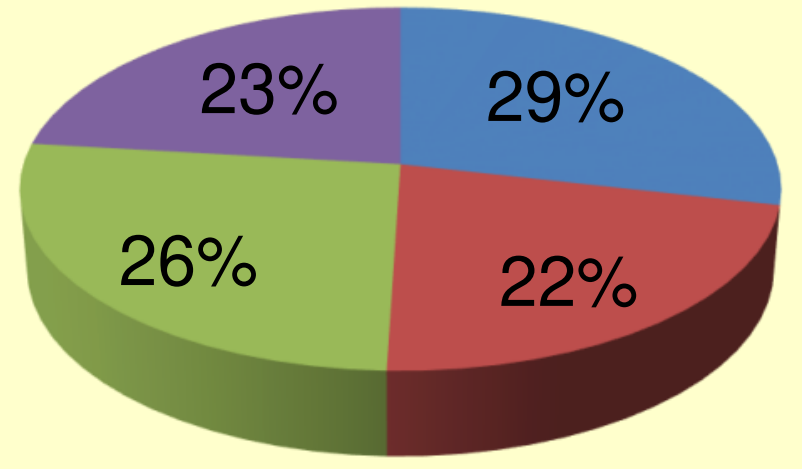

winter

spring

summer

autumn

\section{METHODS}

$>$ DESIGN: Observational cross-sectional study

$>$ STUDY POPULATION: patients hospitalized in Spain whose main diagnosis of hospital discharge was PcP (CIE-9-MC 136.3) from 2008 to 2012.

> VARIABLES: number of patient, HIV status, age, sex, length of stay, weight of diagnosis-related-groups (DRGs), cost of episode, re-admissions within 30 days after discharge, mortality, month and season of hospital admission and risk group for PcP.
Risk factors for PcP in the study population and annual evolution of risk categories.

(CMBD, 2008-2012)

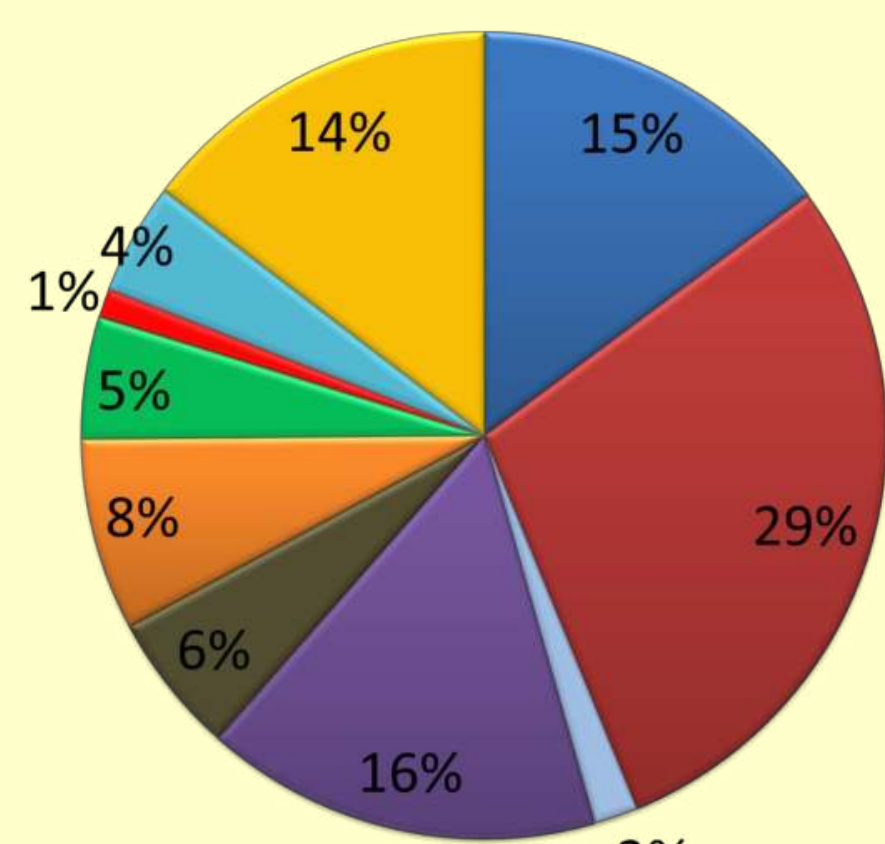

HMT, haematological ; QT, chemใُ Rerapy

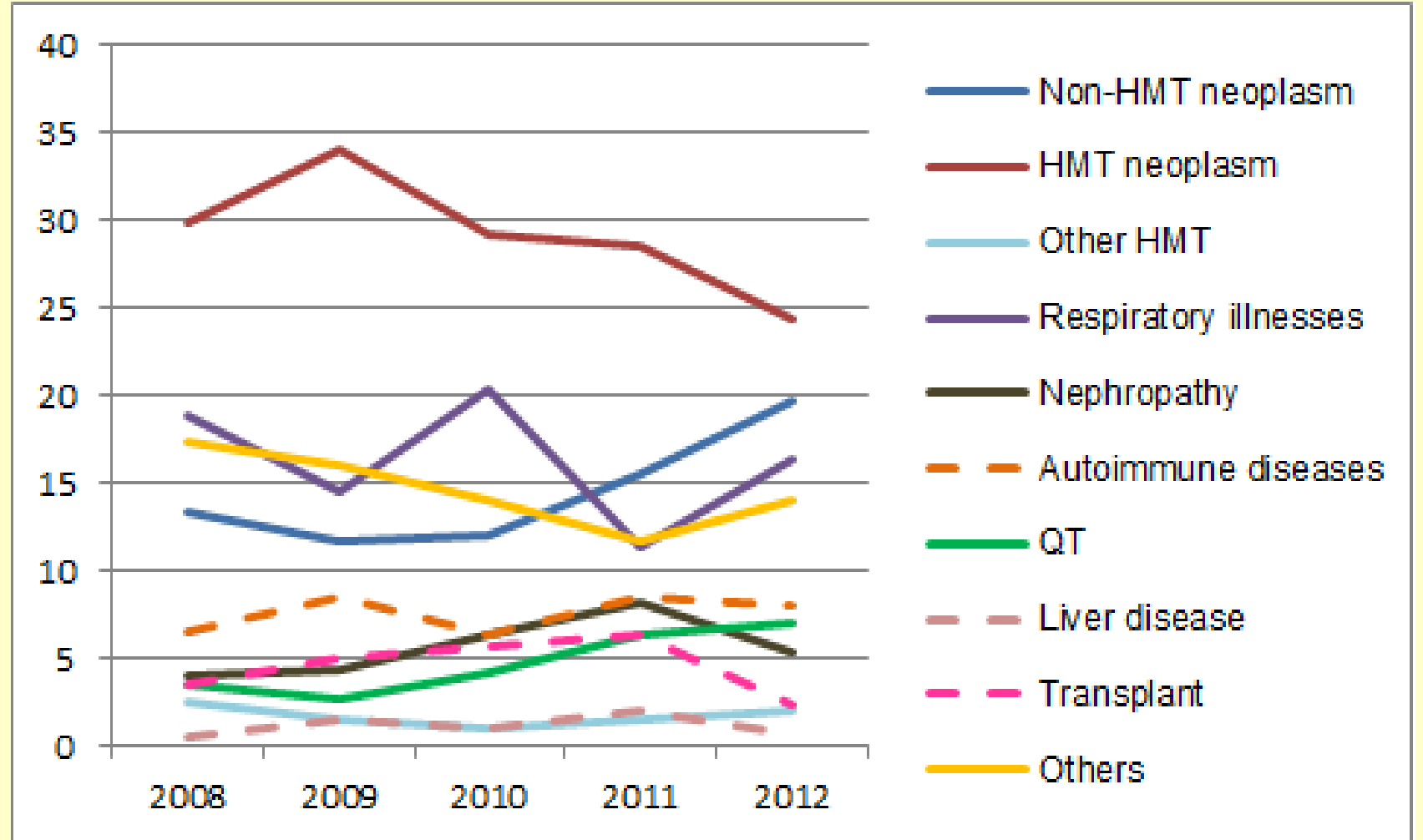

Annual evolution of study variables in patients with PcP without HIV infection hospitalized in Spain (CMBD, 2008-2010)

\section{CONCLUSIONS}

\begin{tabular}{|c|c|c|c|c|c|c|c|}
\hline Year & $\mathbf{n}$ & $\begin{array}{c}\text { Age } \\
\text { (years) } \\
\text { average } \pm \\
\text { SD }\end{array}$ & $\begin{array}{c}\text { Stay } \\
\text { (days) } \\
\text { average }\end{array}$ & $\begin{array}{c}\text { DRGs } \\
\text { weight } \\
\text { average } \\
\pm \text { SD }\end{array}$ & $\begin{array}{c}\text { Costs } \\
\text { (Euros) } \\
\text { Average } \pm \\
\text { SD }\end{array}$ & $\begin{array}{c}\text { Re- } \\
\text { admissions } \\
(\%)\end{array}$ & $\begin{array}{c}\text { Mortality } \\
(\%)\end{array}$ \\
\hline 2008 & 201 & $56 \pm 19,9$ & 25,5 & $\begin{array}{c}2,5 \pm \\
1,9\end{array}$ & $\begin{array}{c}10534,1 \pm \\
7916,8\end{array}$ & 26,4 & 24,9 \\
\hline 2009 & 255 & $55,9 \pm 19,1$ & 23,4 & $\begin{array}{c}2,5 \pm \\
2,1\end{array}$ & $\begin{array}{c}10598 \pm \\
8835,7\end{array}$ & 22,3 & 19,5 \\
\hline 2010 & 193 & $57,2 \pm 17,8$ & 26,3 & $\begin{array}{c}2,6 \pm \\
3,5\end{array}$ & $\begin{array}{c}12567,3 \pm \\
17288,3\end{array}$ & 23,4 & 29,7 \\
\hline 2011 & 256 & $57,8 \pm 17,6$ & 23,7 & $\begin{array}{c}2,5 \pm \\
3,4\end{array}$ & $\begin{array}{c}12631,9 \pm \\
17143,6\end{array}$ & 23,8 & 27,7 \\
\hline 2012 & 299 & $61,5 \pm 17,2$ & 25,8 & $\begin{array}{c}2,7 \pm \\
4,1\end{array}$ & $\begin{array}{c}13827,1 \pm \\
21452\end{array}$ & 28,1 & 26,4 \\
\hline Average & 240,8 & $57,9 \pm 18,3$ & 24,9 & $\begin{array}{c}2,6 \pm \\
3,2\end{array}$ & $\begin{array}{l}12138 \pm \\
15900,7\end{array}$ & 24,9 & 25,5 \\
\hline p & $<0,0001^{\star *}$ & $0,002^{*}$ & $0,644^{*}$ & $0,979^{*}$ & $0,086^{*}$ & $0,572^{* *}$ & $0,115^{\star *}$ \\
\hline
\end{tabular}

SD, standard deviation; DRGs, Diagnosis-related groups; ${ }^{*} \mathrm{ANOVA}$; **Chi-square test

$\mathrm{PcP}$ is still being a frequent disease in Spain, with a steady incidence, due to a significative increase of non HIV-patients, and a parallel decrease in HIVrelated cases.

Mortality among non HIV-patients is high, with a higher age and assitance-related costs being observed, despite no increase in complexity nor stay duration.

Main risk factors for PcP in non HIV-patients are haematological malignancies, chronic respiratory illnesses and solid tumors, but there is still a high number of cases with no predisposing factors identified.

In our research, no seasonal differences in $\mathrm{PcP}$ incidence were seen. 